\title{
Modern city: the system of local government and support of small and medium-sized businesses
}

\author{
Evgeniy Buchwald* \\ Institute of Economics of the Russian Academy of Sciences, 32, Nakhimovsky ave., Moscow, Russia
}

\begin{abstract}
The article analyzes issues related to the impact of various reforms in the sphere of Russian selfgovernment on the development of Russian cities, especially in the context of new territorial administration systems. As the initial premises of such reforms, we consider, first of all, the constitutional innovations of 2020 , which in one way or another affected the economic and legal foundations of Russian local selfgovernment, in particular, through the approval of a single institution of "public power" in the country. The concept of "public authority" is intended to embody the unity and interaction of state and municipal administration in solving the problems of socio-economic development of territories. Further, in the context of the development of cities and their management systems, the tasks of preparing new "Foundations..." of state policy in the field of local self-government are discussed. Emphasis is placed on the need to strengthen the role of municipal management structures in supporting small business forms. The importance of specifying the place and role of various types of municipalities in the practice of strategic planning is shown.
\end{abstract}

\section{Introduction}

The development of modern urban entities in the Russian Federation - from the largest megacities to medium-sized and small urban settlements - is directly determined by the effectiveness of the functioning of local selfgovernment systems operating in them. In turn, this effectiveness largely depends on how effectively local policies for the development and support of small and medium-sized enterprises (SMEs), which generate jobs and the bulk of local budget revenues, are implemented. Today, the role of municipal management in solving the problems of developing and supporting the SME sector of the Russian economy is small. The positive change in this situation is associated with the improvement of the institutional and legal foundations of Russian local selfgovernment and the strengthening of its economic, primarily financial and budgetary component.

The economic and legal foundations of Russian local self-government have not remained unchanged in recent years. However, it is safe to say that 2020 brought a number of important changes in this regard, which give reason to count on new positive developments in this direction. Let us note two important points here.

First of all, we should pay attention to the initiative put forward by Russian President Vladimir Putin in January 2020 at a meeting of the Council for the development of local self-government to prepare a draft of the new "Fundamentals of state policy in the field of local selfgovernment development for the period up to 2030". These "Fundamentals..." should replace a similar 1999 document, which remains in force for the time being. The second of the most important events of 2020 related to the prospects of Russian local self-government is the introduction of amendments and additions to the Constitution of the Russian Federation, approved by the Law on amendments to the Constitution of the Russian Federation of March 14, 2020 [1].

These and other changes and additions to the institutional and legal framework of Russian local selfgovernment should be recognized as very relevant. Indeed, since the adoption of Federal law No. 131 on the general principles of organizing local self-government in the Russian Federation and the implementation of the municipal reform initiated by it, a large number of problems have accumulated, the unresolved nature of which hinders the effective functioning of Russian local self-government. To some extent, the "defects" of Federal law No. 131 and the reform itself were eliminated by amendments and additions to this legislative act. Some progress in this direction was achieved due to the abovementioned amendments to the Constitution of the Russian Federation. However, a number of systemic issues concerning self-government as the most important institution of Russian society and the state still remain open $[2,3]$.

This is largely due to the very limited contribution that local municipal governments in cities can make to national efforts to develop and support the SME sector in the Russian economy. This situation inevitably determines the trend of declining effectiveness of state support for SMEs, which could not be overcome due to some "cosmetic" adjustments in the system of institutions of this support. As a result, the SME sector of the Russian economy in terms of the number of SMEs and the number of employees has been "stomping around" for 10 years,

\footnotetext{
*Corresponding author: buchvald@mail.ru
} 
and its share in the country's GDP also does not show sustainable growth $[4,5]$.

\section{Materials and methods}

The analysis of this situation and its causes is complicated by the low reliability and constant delay in publishing statistical data on the SME sector of the Russian economy, especially at the regional and local levels. This also applies to information on the amount of state support to SMEs, where there is no final data on the amount of funds allocated for this support, in particular, in the context of the Federal budget, as well as regional and local budgets.

In 2019, after a long period of "silence", Rosstat published data on the share of SMEs in Russia's GDP (21.9\% for 2017). According to previously submitted data from the accounts chamber of the Russian Federation, the contribution of SMEs to the Russian economy in 2014 was $19.0 \%$; in $2015-19.9 \%$ and in $2016-21.6 \%$. However, already in 2018, Rosstat recorded a decrease in the share of SMEs in Russia's GDP to $20.2 \%$. This is, in fact, the level that appeared in expert forecasts of the early 2000s.note that despite some differences in national criteria for SMEs, its share in the GDP of developed countries is $50-60 \%$. So, in the UK, this figure is $51 \%$; in Germany-53\%; in Finland-60\%; in the Netherlands-63\%. The passport of the current national project of Russia "Small and medium-sized enterprises and support for individual entrepreneurship" States that the share of SMEs in the country's GDP will reach $32.5 \%$ by 2024. However, in this situation, especially taking into account the negative results of 2020 , this target indicator seems almost unattainable [6].

\section{Results and discussion}

One of the main reasons for the stagnation of the SME sector in the Russian economy should be considered the low effectiveness of measures to support it at all levels of state and municipal administration. If at the sub-Federal (regional and municipal) level, the main reason for this situation can naturally be considered the scarcity of funds for such support, as well as its huge differentiation by region, then at the Federal level, institutional instability in the SME support system had a significant negative effect. This refers to the constant succession of replacements in the Executive authorities or in other institutions that were charged with a leading role in the implementation of the national policy of development and support of small forms of management in the national economy. It should be noted, that such a leapfrog with the parent institution in the framework of the state (federal) policy on SMEs was negatively projected on the regional level of management. For example, after the creation of the State Committee for the Support and Development of Small Business in 1995, similar structures were created in many regions of the Federation, with which the State Committee for the Support and Development of Small Business sought to establish "vertical" interactions. After the abolition of this Federal Executive body in 1998, similar regional structures were significantly reduced, and the practice of clear "vertical" interaction on this issue practically disappeared for a long time. The municipal level of government (with the exception of a few of the largest cities - capitals of the constituent entities of the Russian Federation) has never been fully included in this vertical at all.

Thus, among the main problems of the state policy on SMEs should be considered its "vertical imbalance" in terms of resources used (an ever-growing share of Federal resources in the total amount of state support for SMEs) and institutional instability. The way out of this situation should be considered the restoration of an institutionally and economically balanced vertical in the system of state support for SMEs. The basis for this can be the principle of unity of public power and interaction of all its components, which is now enshrined in the Constitution of the Russian Federation.

It is characteristic that following the approval of the Institute of "public power", the Government of the Russian Federation initiated a reform of the leading Federal development institutions, largely focused on strengthening and interaction of government bodies within the framework of a single system of "public power". Development institutions are one of the instruments of socio-economic policy of the state, focused on solving those tasks that most often cannot be fully provided by market mechanisms of management and require state intervention. In many respects, this concerns the need to implement measures of state and municipal policy for the development and support of SMEs and, of course, its orientation to the requirements of an innovative economy [7].

Development institutions as an instrument of socioeconomic policy of the state have a number of features and advantages that are significant in terms of their potential contribution to the development of the SME sector of the Russian economy. First of all, as an instrument of strategic management, development institutions can function in concert as a creature of the Federal, regional or municipal (city) level. This specificity can be fully projected on the role of specialized development institutions in solving the problems of SME development and support. All development institutions involve close cooperation and co-financing both on the part of the Federation and its subjects, and often on the part of the municipal management level. At the same time, this co-financing from each level of the budget system can be carried out both in direct form (investments in production and infrastructure facilities; subsidies and grants to residents), and in indirect form (tax and customs benefits to residents). Finally, all effective development institutions, including those dealing with the development and support of SMEs, rely on the active use of publicprivate and municipal-private partnership mechanisms.

However, the realization of these advantages is currently hindered by the fact that the concept of "development institution" is not defined uniformly by a legislative act; the legal basis of existing development institutions is regulated by various laws and even separate bylaws. 
It is no coincidence that recently the activities of development institutions (at least in relation to federallevel development institutions) have attracted serious criticism both from official structures (for example, the accounts chamber of the Russian Federation) and from individual groups of experts. First of all, it has been consistently pointed out that budget injections into development institutions do not have the proper effect in terms of increasing the volume of economic activity, investment, jobs, and income at all levels of the country's budget system. Nevertheless, practice has shown that there are very few or no alternative tools for solving the problems of boosting the national economy and its SME segment, other than development institutions. In this regard, the government of the Russian Federation has abandoned the previously imposed moratorium on the creation of new SEZs (special economic zones); the list of TASEDs (territory of advanced socio-economic development) is being expanded, including in singleindustry towns of Russia. For example, 2020 was a record year for the number of new SEZs: 8 such new institutions were created. Currently, there are 36 SEZs operating in the country, which attracted 830 residents with a declared investment volume of more than 1 trillion rubles. However, it seems that positive developments in the activities of development institutions, if at all, are taking place very slowly.

In this regard, in November 2020 the government of the Russian Federation has announced one of the most notable reforms regarding development institutions as organizational structures that play the role of a "guide" from the strategic priorities of the state in the socioeconomic sphere to their practical implementation on the ground. Until recently, there were 40 federal-level development institutions operating in the Russian Federation in the form of various funds, banks, and corporations. The number of regional and municipal development institutions is measured in hundreds. All of them were created to solve various tasks, including those directly related to supporting small and medium-sized businesses, although in reality all effectively functioning development institutions should somehow give an impetus to the spread of small forms of management.

In the course of this reform, a large institutional block was formed on the basis of the State Corporation VEB.RF, which will manage the Corporation for the development of small and medium-sized businesses; the Russian export center; the Russian Agency for export credit and investment insurance; RUSNANO; the SKOLKOVO Foundation; the Fund for assistance to the development of small forms of enterprises in the scientific and technical sphere; the Fund for infrastructure and educational programs; the industrial development Fund. Some of the functions of the eight liquidated development institutions have been reallocated between VEB.RF and federal executive authorities. In particular, such institutions as JSC "Special economic zones"; the Fund for the development of single-industry towns; the Russian Fund for the development of information technologies; Rosinfokominvest; the Agency for technological development; the Agency for the development of human capital in the Far East and the Arctic; The Fund for the development of the Far East and the Arctic; the Agency for attracting investment and supporting exports of the Far East were liquidated (Fig. 1)..

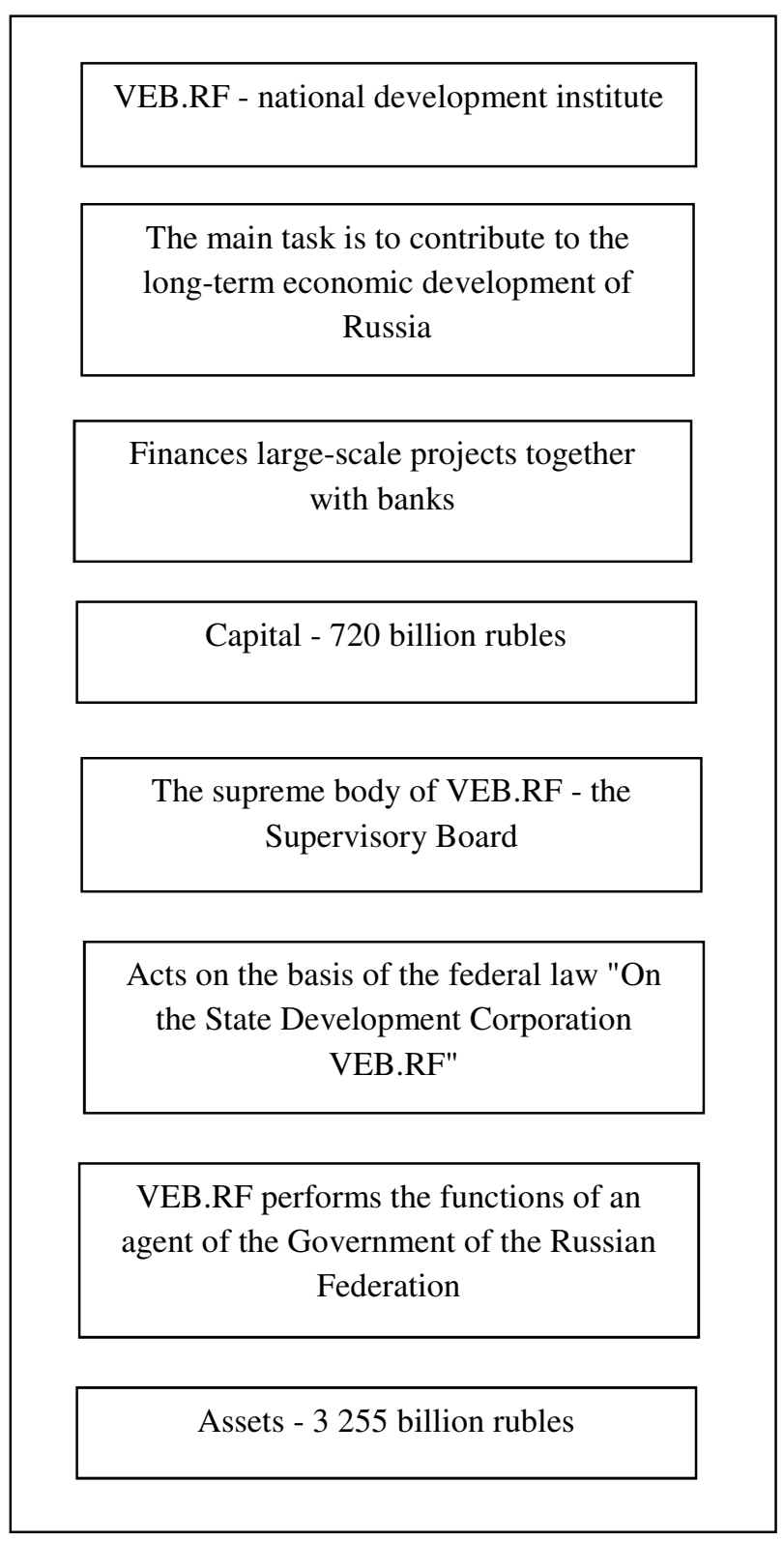

Fig. 1 Characteristics of VEB.RF

In particular, such institutions as JSC "Special economic zones"; the Fund for the development of singleindustry towns; the Russian Fund for the development of information technologies; Rosinfokominvest; the Agency for technological development; the Agency for the development of human capital in the Far East and the Arctic; The Fund for the development of the Far East and the Arctic; the Agency for attracting investment and supporting exports of the Far East were liquidated.

The main focus of this stage of reforms is to increase the socio-economic effectiveness of development institutions, which can lead to an increase in their contribution to the development of the Russian economy as a whole, and to a more consistent solution for the development and support of SMEs. One of the conditions 
for moving forward on this path is to restructure the functioning of these institutions on the principles of unity and interaction of all levels of public power in the country. In other words, one of the main tasks in the activities of Russian development institutions is to really unite or integrate the efforts of Federal, regional and municipal government bodies on the basis of public authority in solving the most important economic tasks, including the development of small and medium-sized businesses. At the same time, we are talking about combining their financial, as well as organizational, information and human resources; about forming a unified legal and methodological framework for all issues of socioeconomic policy that are solved with the participation of development institutions.

In the field of development and support of SMEs, the main task of development institutions as the Federal, regional and municipal level is that, on the one hand, to help SMEs' "start-ups" to attract investment for the development of its business, and on the other hand encourage every startup was understandable and effective growth strategy, having a good marketing and other support. The role of development institutions is also to avoid getting SMEs into certain critical situations that can put entrepreneurship on the brink of survival. It is obvious that such effective monitoring of SMEs can be implemented only at the municipal level. At the same time, it is important to form a practice in which the interests of SMEs are realized not only through specialized institutions of its support, but also through all other institutions of both sectoral and spatial development located in the respective territories. This will significantly increase the effectiveness of the state-municipal policy of SME support [8].

At the same time, it should be borne in mind that strengthening the contribution of development institutions to solving key issues of SME development and support depends not only on the quantitative and qualitative performance indicators of these institutions, but also on how clearly this range of tasks is positioned in the institutional and instrumental framework of strategic planning practice. However, now the institutional and instrumental apparatus of strategic planning in the Russian Federation does not have a clear structuring and goal orientation. Thus, the same goals of state policy in relation to SMEs are implemented through a system of state programs, federal and regional projects, Federal and regional development institutions, etc. of course, this situation creates additional difficulties for positioning development institutions in the system of instruments of development policy and support for SMEs. In this sense, it is extremely important that participation in the development and support of SMEs becomes not just a "burden" for the entire range of development institutions, but also relies on a clear definition of the tasks that each of these institutions should focus on, according to its general functional specialization and the specifics of the region of its spatial localization [10].
To solve this problem, it is important to record the following conclusions. First, it is desirable to develop and adopt a single Federal law "On development institutions of the Russian Federation", including specifying the role of these institutions as one of the instruments of SME development policy and support. Secondly, the role of "development institutions" as one of the instruments of SME support policy can be effectively implemented only on the basis of federalization of this policy and balanced distribution of the economic resources available to this policy at all levels of public authority [9, Pp. 97-108]. It is necessary to expand the economic and other opportunities of the municipal level of management to support SMEs, including by implementing targeted municipal programs, activating the activities of municipal "development institutions" aimed at developing and supporting SMEs, primarily in the largest cities of Russia [11].

\section{Acknowledgements}

The article was prepared with the support of the Russian Foundation for basic research in the framework of scientific project No. 20-010-00120-A "Small and medium-sized entrepreneurship as a tool for regulating the spatial structure of the Russian economy".

\section{References}

1. E.M. Buchwald Federalism. 1, 16-20, (2021)

2. O.N.Valentik Innovations. The science. Education. 28, 114-121, (2021)

3. $\quad$ E.V.Kiskin Federalism. 4 (100), 107-126, (2020)

4. S. V. Nekrasova Russian economic bulletin 3 (3), 116-120, (2020)

5. E. M. Buchvald Bulletin of Vladimir state University named after A.G. and N.G. Stoletov. Series: Economic Sciences, 1 (23),114-128 (2020)

6. A.M. Morozova Scientist's Rostrum, 10, 370-373, (2020)

7. E.M. Kobozeva, T.V. Vorobeva Innovative economy: prospects for development and improvement, 35 (47), 40-47 (2020)

8. A.V. Polyanin, Yu.P. Soboleva, V.V. Tarnovsky Bulletin of Omsk University. Series: Economy. 18(1), 32-44, (2020)

9. Yu. V. Vertakova Economic Sciences. 13(4) (2020)

10. Z. Mingaleva, N. Pazdnikova, E. Mitrofanova Asian Social Science, 10(24), 257-262 (2014)

11. O.V. Butorina, N.P. Pazdnikova, Y.V. Karpovich Espacios 39(27) 2018

\section{Conclusion}

